\title{
Balancing basic and applied research
}

\author{
In a time of economic changes and stagnating support from the government, universities \\ have to restructure and reshape their mission • by André Oosterlinck, Koen Debackere \& \\ Gerard Cielen
}

Traditionally, basic and applied research were seen as activities of a different nature, carried out by different institutions and financed from different sources. But in the 1970s and 1980s, the information and communication technologies (ICT) - later reinforced by biotechnology_started a trend in which it became increasingly important to turn scientific research into concrete products. Whole industries were built around the

But the 'intrusion' of private enterprises and funding into the academic world is not to everybody's liking. Some critics fear that financial dependence on private sources will diminish the independence of the university and its scientists (Nature, 2001). Others see conflicts of interest in publishing results that can be developed into potential products, and fear that private stakeholders will eventually undermine some basic principles of research,

\section{Whole industries were built around the notion of developing commodities and services from basic research}

notion of developing new commodities and services from basic research as quickly as possible. As a result of these new economic developments, the strict division between basic and applied research in those fields has weakened, until the boundaries have become obsolete and sometimes artificial.

Consequently, the way in which researchers co-operate and forge partnerships with industry, as well as the regional importance of academic research and its role in the local economic setting, changed dramatically during the 1990s. While universities were predominantly government funded with the logical consequence that research results were made fully available to society as a whole, more recently they have evolved into institutions funded through a variety of sources and with different stakeholders, who expect the knowledge generated to be protected and exploited in an appropriate way. Of course, these changes have been more prevalent in fields such as biomedical research or ICT where basic research can be translated fairly rapidly into viable applications, unlike in other domains such as astronomy or particle physics. most notably the free exchange of information. They also believe that the reputation of scientists as independent experts might become damaged if they have financial interests, for instance as shareholders of biotechnology companies (Hall and Scott, 2001).

But a lot of this criticism disregards the potential benefits to be gained from private and public co-operation in the academic world. Indeed, this new strategic attitude promises to create advantages both from a general economic point of view as well as royalties that can be reinvested into research and thus strengthen
What are also not being taken into account by many critics are increasing budget constraints, a problem that has intensified over the last decade. While governments have been reducing spending on basic science, research has become more expensive and increasingly under pressure to contribute to economic growth. These constraints, as well as the traditional dualism between basic and applied research, have weakened the European position in research and development (R\&D). However, many problems of both basic and applied research are comparable: the total R\&D budget of the EU member states is substantially lower than that of Japan or the USA; the employment of researchers in European industry accounts for only 2.5 per thousand as compared with 6.7 per thousand in the USA; the brain-drain that was observed at the beginning of the 1990s is still ongoing and, finally, many studies indicate that Europe is less innovative and losing ground in several important markets, particularly ICT and biotechnology (European Commission, 1996). Thus, it is not necessary and rather counterproductive to worry about the appropriate distinction between basic and applied research when, in fact, they share many problems.

\section{Universities have evolved into institutions with different stakeholders who expect the knowledge generated to be protected and exploited in an appropriate way}

the universities' research base. Varga (1998) confirms that it is precisely the mix of different types of research and development activities that has the most significant impact on science's contribution to the economic performance of individual countries and regions.
Instead, a proper mix of basic and applied research can be a large contributor to local economies, creating highquality jobs as well as revenues both for universities and society. Varga (1998), when investigating the impact of both R\&D expenditures and of academic 


\section{viewpoint}

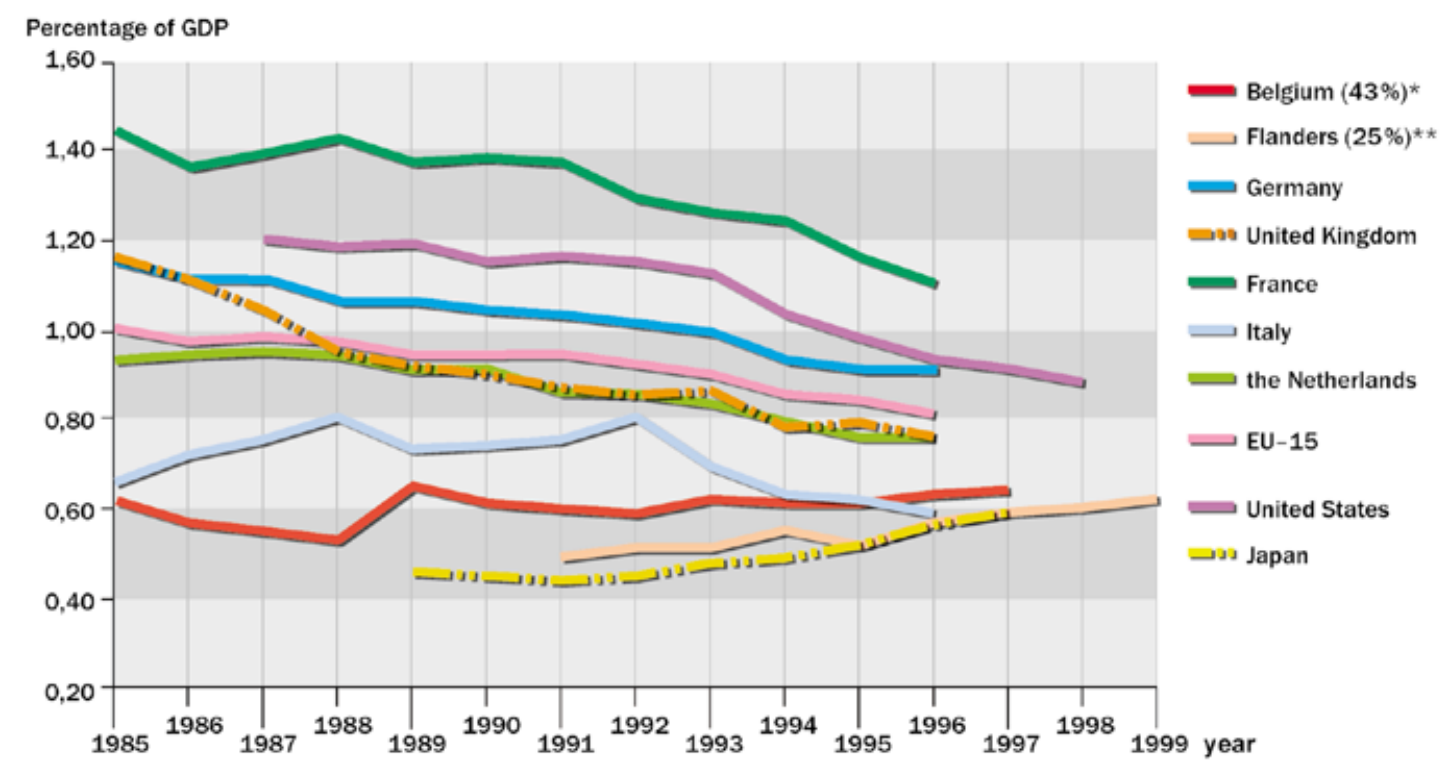

Fig. 1. Governmental R\&D expenditure in some EU countries, the USA and Japan as a percentage of GDP $(* 43 \%$ of structural funding of universities included in the R\&D statistics, $* * 25 \%$ of structural funding of universities included in the R\&D statistics).

research in 125 regional statistical entities-so-called 'Metropolitan Statistical Areas' or MSAs-in the USA, found that R\&D employment in industry has a positive effect on the innovation output of now changed. Besides nurturing human talent, universities are now expected to devote at least part of their research to solving practical problems. A recent study (Verbeek et al., 2002) modelled the link-
Critics fear that financial dependence on private sources will diminish the independence of the university and its scientists

each region. Also, a region's university level research can only have a positive effect on that innovation output if there is sufficient interaction between academic research and a flourishing entrepreneurial 'texture' of high-tech ventures and startups. But an overly strong presence of large, established manufacturing-intensive firms appears in turn to have a significant but negative effect. In short, the picture that emerges from these studies emphasises the need for sufficient diversity and critical mass in terms of the interactions between university research on the one hand and a high-tech, R\&Dintensive industrial environment on the other.

The interaction of universities with the economy has also become more varied in nature. Whereas traditionally the education of students tended to be the major mechanism by which universities transferred their know-how to society, this has age between science and technology by assessing scientific journal citations within patent documents. It shows that the distribution is very skewed-about $90 \%$ of all references in the patent literature occur within less than $20 \%$ of all technology domains, with life sciences and ICT being the leading areas. Furthermore, whenever the science linkage occurs, there is a significant correlation of articles published in so-called basic science journals to the patent literature; in other words, there is a direct link between basic research and technological application. These findings again support the hypothesis that the boundaries between basic research and technological applications, at least in certain areas, are now blurred.

For many research groups, participation in industrial research projects often increases their visibility, profile and scientific importance. In some cases, this attitude results in a change of mission, and, consequently, in an emphasis on short-term and policy orientated research. In many European countries, this trend has been enhanced by the stagnation, or even reduction, of government support for basic research. In addition, the EC has created new funding opportunities for 'problem-solving', 'pre-competitive' and applied research, but a structured funding of basic research is not yet a priority (Goffeau, 2001). These trends in European R\&D funding lead to problems in innovation behaviour, which have been documented previously in the 'Green paper on innovation in Europe'. Figure 1 shows a certain convergence in R\&D spending at the international level. For instance, in 1990 Japan's R\&D budget represented $0.5 \%$ of its Gross Domestic Product (GDP), compared with $1.4 \%$ in France. The comparable percentages in 1996 showed a narrowing of the gap: $1.1 \%$ for France and $0.6 \%$ for Japan. Is this purely coincidental or are there specific reasons behind this trend? The ongoing internationalisation of science makes knowledge accessible anywhere in the world. The idea of 'anchoring knowledge' in a country or region is extremely difficult in an economic environment dominated by multinationals that buy knowledge or technology where it is available in order to implement it where it is needed. 


\section{viewpoint}

Therefore, why should a country or region invest substantially more in R\&D than its neighbours?

On the other hand, the opportunities for industrial contracts and partnerships have increased dramatically. In some cases, academic institutions have gradually transformed themselves into partially or

A proper mix of basic and applied research can be a large contributor to local economies

largely self-financed 'profit' centres. One can hardly believe that this trend will become a dominant factor, but it shows that the academic world is undergoing significant restructuring and reshaping. And mobility of scientists and rapid exchange of knowledge via the Internet will lead to even more changes. Indeed, the European research centres should also take into account that 'competition on the knowledge market' is growing very rapidly. Europe is still at the forefront of scientific progress, but its historical strength in scientific research is more 'volatile' than ever before. In the long term, one may expect that new economies will establish their own centres for the development of new knowledge.

In order to maintain Europe's level of scientific excellence, it is thus desirable and necessary that R\&D investments become a common top priority, comparable to the financial objectives that were imposed to create the European Monetary Union. A common 'Maastricht standard' for R\&D funding should therefore be created: $1 \%$ of the GDP to be spent on R\&D would seem to be a feasible minimum.

These developments on a European and International level are now confronting the universities with two important challenges. In many countries, government funding for basic research is stagnating and, in addition, a considerable share of it is now provided on a contract basis, conditional on specific, measurable shortterm objectives. And this will eventually impinge on academic freedom and creativity due to the workload caused by such short-term projects-creativity requires a maximum degree of independence as well as a reasonable assurance of stable, long-term funding. The dilemma between the objective of additional funding versus the objective of academic freedom is a point of concern for nearly every modern university laboratory.

Indeed, when Marcia Angell (2000) analysed clinical research and its ties to the pharmaceutical industry, she drew some conclusions that, in fact, affect the whole academic research structure and reinforce some of the criticisms mentioned earlier. Many governments now have created specific programmes to encourage partnerships between academia and industry to facilitate technology transfer and to provide an additional source of funding for basic research. The most remarkable conclusion that Angell draws, however, is the concern that such partnerships with industry may bias research, and ultimately influence the 'scientific judgement' of the scientist involved.

These findings have raised some important questions. Should universities adopt stronger conflict-of-interest guidelines, not only to meet the traditional university mission, but also in order to protect the sustainable progress of basic research? Should universities enforce rules with respect to personal engagements of academic staff in industry? Should scientific journals mention the source of funding for the projects leading to their published articles? And should universities maintain the balance between basic and applied research in each of their research groups?

\section{The dilemma between the objective of funding versus the objective of academic freedom is a point of concern for nearly every modern university laboratory}

. The interviewees unanimously responded that 'Our greatest sources of strength are our universities. They are the "Mecca" of higher education worldwide'. In general, business holds the view that universities add value by focusing primarily on fundamental research as well as on high-level teaching.

But those representatives from US industry also voiced concerns about the university research sector. First, the changing attitude of universities towards intellectual property ownership was expressed by several interviewees as: 'Frictions are beginning to appear [between industry and the university sector] as the university tries to own all of the intellectual property that it has produced. The university connection has been very important to us, but universities are getting greedy.' A second problem-already mentioned, but confirmed by US industrialists-is that government funding of the university sector appears to be decreasing, which weakens a critical link in the innovation chain. From the university's point of view, this second problem is closely related to the first one: with their efforts to capitalise on intellectual property, universities are attempting to collect royalties to compensate for reductions in government support.

These significant economic developments in recent years have affected the research-related mission of the academic
But these questions might be missing the point. Indeed, because of its added value for both universities and industry, efforts to enhance the transfer of technology will undoubtedly play an essential role in future science policies. A rapid translation of new knowledge into technologies reduces the overall costs of research and facilitates the launching of new products or services onto the market place. But the main task for the academic sector is the creation of new knowledge. A recent study, New forces at work: industry views critical technologies', based on a number of interviews with high-level industrialists in the USA, confirmed the importance of universities in the innovation chain (Popper et al., sector. Universities are still at a loss as to how best to react to these changes and are becoming more diverse in structure and more orientated towards social and economic challenges. But this is sometimes at the expense of basic research, the most important task of academia and its true strength. These trends raise many questions concerning new balances between research and knowledge transfer as well as between industrial partnerships and academic freedom. Those universities that face these challenges and actively manage these balances will maintain their unique position as important players in long-term basic research and are likely to be the most successful ones in the future. 


\section{viewpoint}

\section{References}

Angell, M. (2000) Is academic medicine for sale? N. Engl. J. Med., 342, 1516-1518.

Editorial (2001) Is the university-industrial complex out of control? Nature, 409, 119.

Goffeau, A. (2001) A plea for funding 'small' basic research in Europe. EMBO rep., 2, 1057-1060.

Hall, Z.W. and Scott, C. (2001) Universityindustry partnership. Science, 291, 553.

Popper, S.W., Wagner, C.S., Larson, E.V. and Don, B.W. (1999) New forces at work: industry views critical technologies. Rand Corporation, Santa Monica, CA.

Varga, A. (1998) University research and regional innovation: a spatial econometric analysis of academic technology transfers. Economics of Science, Technology and Innovation, Vol. 13.
Kluwer Academic, Boston, MA.

Verbeek, A. et al. (2002) Linking science to technology: using bibliographic references in patents to build linking schemes. Prog. Scientometrics, in press.
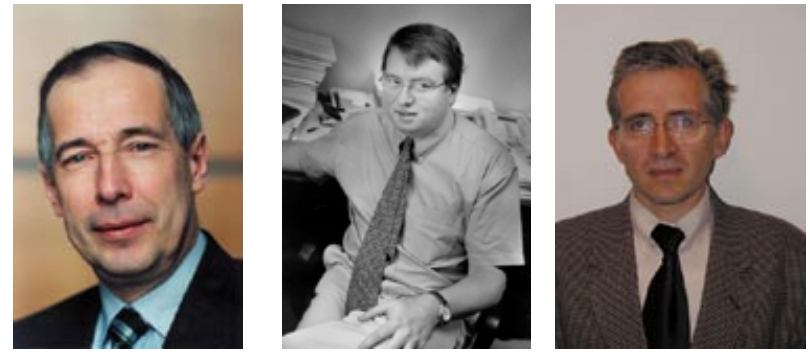

André Oosterlinck is Rector, Koen Debackere is Professor for Economics and Gerard Cielen is staff member of the Research Co-ordination Office at

the Katholieke Universiteit, Leuven, Belgium. E-mail: Gerard.Cielen@ doc.kuleuven.ac.be

DOI: 10.1093/embo-reports/kvf016

\section{Promoting women}

\section{Mentoring is a helpful tool not only for helping women to climb the career ladder but also to make men more aware of the specific problems women face • by Heike Mänz \& Gábor Rossmann}

Our chief want in life is someone who will make us do what we can.'-Ralph Waldo Emerson

All human beings are supposedly equal. But by looking at the gender distribution in high-level management positions in industry, academia and public services, one cannot escape the fact that men seem to be more equal than women. This is not a satisfactory situation, particularly in an economy that depends on welltrained and educated professionals, who are increasingly in short supply. Numerous strategies are being employed to close the gender gap, either through legislation or through raising awareness and training. Here, we would like to describe our company's experiences with introducing mentoring programmes that aim to increase the number of women in leading positions.
This strategy actually works both ways by providing better training for women while
The European Technology Assessment Network report clearly illustrates the

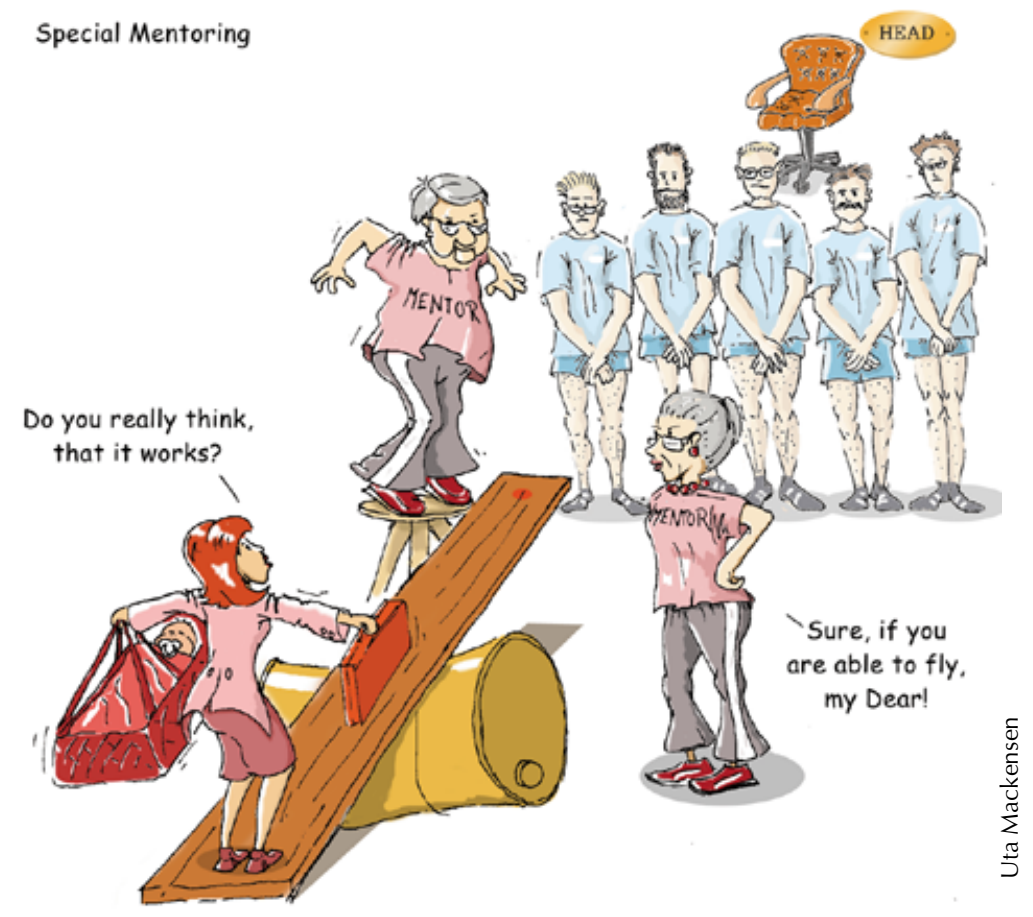

acquainting their male superiors with the specific problems faced by the opposite sex.

situation of women in academia. 'The status quo [of women in science] is wasteful and inequitable. The abuse of the "old boys' network" in some of our scientific institutions is an anachronism. The emphasis on gender in hiring and promoting has no place in modern institutions. It is not only bad for science but it denies many women the benefits of a scientific career that are enjoyed by men, such as the satisfaction of curiosity, setting one's own priorities, some status, and a certain degree of autonomy.' (ETAN report, 2000).

The main reason for this unsatisfactory situation is the 'glass ceiling', symbolising all invisible structural and cultural barriers that prevent a woman from climbing the career ladder. But 